\title{
Blogging Gratifies Engagement Need for Internet Users in Media-Constrained Environment
}

\author{
Bahtiyar Kurambayev ${ }^{1}$ \\ ${ }^{1}$ Assistant Professor, Department of Media and Communications, KIMEP University, \\ Almaty, KAZAKHSTAN
}

\begin{abstract}
Results of survey from a snowball convenient sample of Kyrgyz bloggers $(\mathrm{N}=263)$ showed that internet users are motivated primarily to blog for information, recreation and engagement needs. The information motivation was the strongest motivation among the survey participants while engagement was the strongest factor in predicting the frequency of their blogging activities. The results revealed a negative relationship with recreation motivation and blogging, suggesting internet users with recreation motivation tend to blog less compared to others. The data also revealed no gender difference among bloggers of Kyrgyzstan contradicting existing scholarship. This finding is a surprising in a context where women are excluded from decision making processes. The results are explained via uses and gratifications theory.
\end{abstract}

Keywords: blogging, Facebook, social media, gratifications, Kyrgyzstan 


\section{Introduction}

The term 'blog' became the top word in 2004 by a US dictionary publisher (BBC, 2004) and since then, a great deal of research has been undertaken globally to examine a variety of issues in blogging. There are studies about news reporting through blogs (Schultz \& Sheffer, 2008; Bruns, 2006), blogging as a religious practice (Cheong, Halavais, \& Kwon, 2008), blogging as a means of grieving (DeGroot \& Carmack, 2012), blogging about gay rights, or war in Iraq (Pole, 2010), blogging about health issues (Rains \& Keating, 2015). Other studies examine implications of blogging on politics and its financial impact on elections (Bahnisch, 2006). Some blogs are devoted to "mobilizing people for rallies, protests, or marches, petitions, fundraising, and legislation" (Pole, 2010, p. 12). However, little empirical knowledge is available in blogging about Kyrgyzstan and Central Asia, a scholarly gap according to Freedman and Shafer (2012) who argue that "there is no shortage of potential research topics pertaining to the press, journalism and mass communication in the region, given globalization and the rapid changes in communications technologies, such efforts would be particularly timely" (p. 124). Cardoso, Liang, and Lapa (2013) argue that research in non-western context might bring fresh ideas and different perspectives that may challenge the dominant body of knowledge. This study aimed to fill this void by examining motivations of bloggers in the context of Kyrgyzstan.

The goal of this study was to contribute to the overlooked non-English language blogging research because the vast majority of academic work focused on the United States (Perdersen \& Macafee, 2007). This study specifically examines three questions: RQ1: What are Kyrgyz internet users' primary motivations for blogging? RQ2: How does gender play a role in blogging motivation? RQ3: What motivation predicts the most of frequency of blogging?

To answer these questions, this study surveyed bloggers in Kyrgyzstan. For theoretical support, the author drew on uses and gratifications theory. This theory explains internet users use blogging because they have different needs and wants (Katz, Blumber, \& Gurevitch, 1974).

Plethora research studies suggest that people have different reasons for blogging including to kill the time, to share feelings, to inform about one's life experiences (Dumova \& Fiordo, 2012) just to list a few. Dumova and Fiordo argue that there is still little serious scholarship 
regarding blogging from cross-cultural analysis on a global scale. Existing literature, however, suggests that Latin American bloggers write blogs primarily for selfdocumentations, self-expression, information sharing, and socialization (Bronstein, 2012). Even though these scholars did not specifically examine blogging phenomenon, but Cardoso, Liang, and Lapa. (2013) argue that Asia is more "entertainment" driven in its use of the internet. Cardoso et al. (2013) argue that Anglo-speaking world is divided, specifically, Australia and US tend to use internet for entertainment, while in the U.K. internet users focus more on communication and information.

This paper begins by exploring in more depth rationale for examining abovementioned questions using Kyrgyzstan bloggers and then explains how uses and gratifications theory relates to this research. Part three focuses on the methodology used in this study. Part four analyzes the findings and then final part draws upon the discussion and the conclusion.

\section{Literature Review}

This study is vital for several reasons. First, freedom of expression is restricted in Kyrgyzstan. Therefore, it has scholarly interest to understand how and why internet users blog in this restrictive environment and whether political restriction of freedom of speech plays a role in it. News outlets are under government control and journalists are restricted in what they can and cannot report. This is why journalists and activists self-censor themselves, and those who do independent journalism or others who speak up about government incompetence get harassed, attacked, arrested, and some even risk their lives to speak up (Kurambayev, 2016; Bowe, Freedman \& Blom, 2012, Freedman, 2012; Freedman \& Shafer, 2012; Pitts, 2011). Freedom House reports that the judiciary is not independent and corruption among judges is widespread suggesting little regard to a rule of law. In this context, internet remains the only avenue for self-expression (Kulikova \& Perlmutter, 2007). Second reason is that it is a unique location for scholarly examination because little is known about this part of the world to outsiders and while internet is still relatively new, it is logical and timely to undertake this study. Freedman and Shafer (2012) noted that scholars have barely scratched the surface in studying Kyrgyzstan. They do not argue that international scholars deliberately overlook Central Asia but rather certain challenges impede them in undertaking such studies including travel restrictions by the governments, language barriers, local unfamiliarity with the idea of research among many other reasons. During Soviet years, 
independent scholars were not allowed to pursue research (Freedman \& Shafer, 2012) and Soviet researchers were often forced to censor and manipulate their own findings (Tucker, 2014). After the independence in 1991, the country allowed some foreign research by cooperating with international organizations, but news reports suggest Kyrgyz government may still deny an entry into the country to international researchers and/or deport from the country. Kendzior says that Kyrgyzstan has become a "dangerous place" for researchers (Kendzior, 2015, para. 16) because these "governments will go to repress their own citizens, and in turn, anyone who wants to know what those citizens are thinking" (para. 16). Therefore, peer review is almost entirely absent in most international academic journals.

\section{Internet Use in Media Constrained Kyrgyzstan}

The majority of Kyrgyz internet users are in major cities, particularly capital Bishkek cities. Eighty percent of internet users in Kyrgyzstan are under 35 years old (Srinivasan \& Fish, 2009). Seventy seven percent of all internet users are located in Bishkek capital city (Warf, 2013). It is widely thought that every third resident of the country has access to the internet but no accurate data is available. The number is growing because of wider internet penetration and growing number of private companies offering internet connection to households.

Internet is cited to have played an instrumental role in the organization of mass protests in Kyrgyzstan against the government in 2005 that led to the ousting of then President Askar Akayev (McGlinchey \& Johnson, 2007) suggesting that internet users active use the online platforms. Further support comes from Srinivasan and Fish (2009) said there was a growth from personal to political oriented authorship. However, Wilkinson and Jetpyspayeva (2012) undertook one of the first studies examining specifically the blogging phenomenon in Kyrgyzstan in 2012. They argued that internet users generally are passive consumers because they only consume rather than create content.

Kyrgyzstan's internet has been described partly free, but recent developments suggest that Kyrgyzstan is moving toward more control over the internet platforms. In recent months, the number of internet users getting into various levels of troubles. For example, some internet users were questioned and then warned by national security agency; others were dismissed from job for comments on social media and taken to court for critical comments. Foreign 
nationals were deported from the country for social media comments. Kyrgyz government has a trolling unit as part of presidential administration to manipulate public opinion on a variety of issues (Kloop.kg, October 2, 2015). These trolls are instructed every day by their coordinator to spread certain opinions about a variety of political issues- be it global issue or domestic matter and discredit and attack those who criticize the Kyrgyz government officials.

In this context, it is logical to examine first about why people use internet. In other words, RQ1: what motivates internet users in Kyrgyzstan to blog?

\section{Blogging Motivations in International Context}

In an international setting, very few studies exist. Those available literatures suggest people blog in different places for divergent motivations because characteristics of these various parts of the world are different. For example, Sepp, Liljander, and Gummerus (2011) were concerned about motivation of bloggers from Estonia. They argued bloggers in Estonia are primarily motivated by enlightening others, social gratifications of communication, image management. British bloggers use the internet platform mainly for leisure activity (Pedersen \& Macafee, 2007). In a somewhat comparative approach, Bronstein (2012) examined Spanish-speaking international bloggers across six countries in Latin American continent. Bloggers represented Mexico, Colombia, Peru, Chile, Argentina, and Ecuador. The author argued that Spanish speaking bloggers are motivated by self-documentation, self-expression, information sharing, passing time and socialization In a study of Saudi Arabia, Qatar, Lebanon, Bahrain, Jordan and the United Arab Emirates countries in the Arab region, Martin and Schoenbach (2016) argued that bloggers in Arab countries mainly engage in sharing photos online and participating in online chats. Limited research suggests that there is a need more cross-cultural analysis of blogging on a global scale (Dumova \& Fiordo, 2012) while acknowledging the diverse factors such as social demographics (age, education, income, ethnicity, geographic location), country/regional differences (national wealth, culture, religion, etc), political context (democratic or authoritarian), media culture and many other factors.

\section{Gender Differences in Blogging}

Existing literature suggests that that there is a gender difference in what motivates men and women blog. Fullwood et al. (2014) have reported about gender differences in blog because 
of different needs and wants. They argue that men tend to blog about events, whereas women tend to blog about their own lives and experience. Other studies also support that idea of gender differences in blogging exist. For example, women are said to be motivated by selfexpression whereas men create blogs to share information ( $\mathrm{Li}, 2007$; Lu \& Hsiao, 2009; Chen, 2012). Forming relationships is among the motivations for blogging and wider social use. In this regard, men used blogging for forming new relationships, while women reported using it for maintaining already existing relationships (Muscanell \& Guadagno, 2012). In this context of Kyrgyzstan, gender is an important variable to explore because of numerous reasons. For example, women are still excluded from decision making and violence against women is widespread. The country also faces bride-kidnapping practices, early marriages and physical abuses. "The negative reinterpretation of some cultural and social practices increasingly restricts women's rights to control their own lives" (United Nations, n.d.). Further supports come from recent news reports when male lawmakers decided to quit the discussion about women's rights in parliament (such as female education and measures against domestic violence) on June 22, 2017. Out of 101 lawmakers present at the session, only 16 remained to discuss and vote for the women's rights in Kyrgyzstan (Djanibekova, 2017). Therefore, it is proposed how a gender plays a role in blogging among internet users of Kyrgyzstan.

\section{Blogging under Authoritarian Context}

Blogging under authoritarian countries can be very risky. For example, Azerbaijan actively attempts to control wider social media platforms including bloggers so they do not get involved in politics. Those who do get involved, Pearce and Kendzior (2012) argue, can be imprisoned for their blogging and social media posts while "arrests and prosecutions of bloggers and online activists have become the norm" in Kazakhstan ((Niyazbekov, 2016, para. 18) for their critical comments on social media (Freedom House, 2015; Savchenko, 2016). Tajikistan asserts pressure on internet users critical of the government (Transitions Online, 2013) and blocks most popular blogging platforms and other social media sites (Shafiev \& Miles, 2015). In fact, security services of Tajikistan have two special cybersecurity units to monitor and control citizens' online activities including by keeping detailed records of SMS, mobile messages, social media comments and anyone visiting "undesirable" websites (Global Voices, July 31, 2017). The authorities of Belarus, Russia and Uzbekistan actively use cyber-attacks against those independent media outlets and 
prominent bloggers and wider online activists are subjected to intimidation, physical attacks and arrests for their social and political writings (Ryabinska, 2013). Ryabinska also noted that post-Soviet governments also become active players in the online environment by hiring prominent bloggers to promote their own official agenda along with manipulation goals of online discussion forums, social networks and blogging platforms. As an example, Ryabinska noted, the government of Russia hires youth organizations to create pro-Kremlin comments and thwart online discussions that may be perceived against Kremlin. Overall, authoritarian governments such as Iran, Egypt, Russia and other countries maintain extensive, multilayered systems of censorship and surveillance (Calingart, 2010) including blocking content about government incompetency or abuse of power, filtering and censoring where humans manually remove certain blog posts along with punishing other players such as internet providers or cafes. Calingart also notes that bloggers can be "subjected to 24-hour surveillance, harassment, arbitrary arrests and even torture" (p. 69).

\section{Uses and Gratification Theory}

It is important to examine the internet user motivations in blogging especially in a context where people may have little freedom to express themselves or discuss issues that matter to them on a daily basis. The analysis of internet users' motivation in Kyrgyzstan to blog can be analyzed through uses and gratification theory. This theory has been widely applied in mass communication research to audience. A considerable amount of literature has been published on uses and gratification theory application to blogs and other social media. Overall, Katz, Blumber, and Gurevitch (1974) stated that the uses and gratification is derived from (1) the social and psychological origins of (2) needs, which generate (3) expectations of (4) the mass media or other sources, which lead to (5) differential patterns of media exposure (or engagement in other activities), resulting in (7) other consequences, perhaps, mostly unintended ones (p. 20). Thus, media users are indeed active participants rather than previously thought passive users because they make conscious decisions in media use, what types of, when and under what circumstances unless no alternatives for audience members. So, this research proposes that internet users in Kyrgyzstan are motivated to blog by their information, entertainment and communication needs and wants. 


\section{Method}

A 22-question survey was conducted between September 1 and September 30, 2016. It was distributed online using the Qualtrics survey platform, and respondents participated on their own computers. They survey was offered in English, Russian and Kyrgyz languages and bloggers chose the language in which they wanted to take the survey in. Of the 374 of respondents' access to the online questionnaire via snowball approach 263 completed the survey resulting in a 70 percent response rate

\section{Sample}

It is impossible to know the full population of bloggers in the context of Kyrgyzstan because there is no such central registry database. Therefore, author employed a nonprobability sample by sharing the link with bloggers with whom the author knew and asking them to share the survey link with their own networks. This nonprobability method does not offer generalizable results, but it provides an exploratory understanding of the focus of this study. No one under 18 was invited to participate in this study. Participation was voluntary and respondents were offered the option to stop at any time or complete the survey partially. Once a respondent completed the survey, he/she no longer had access to the survey to avoid coverage error.

Approximately $62 \%$ of the respondents were female $(n=163)$ and $38 \%$ were male $(n=100)$. Roughly $32 \%$ of the respondents said that they were studying at a college or university at the time of data collection, followed closely by completed high school at $31 \%$, and $29 \%$ made up with college or university graduates. The remaining included $4 \%$ with master's degree and $4 \%$ selected that they have incomplete high school education.

Almost half (54\%) of survey participant bloggers said that they blog in Russian, $28 \%$ write in the Kyrgyz language, $13 \%$ blog in English, 3\% in other unspecified languages, followed by almost $2 \%$ blogged in Uzbek language. The majority (36\%) of bloggers indicated that they use Facebook Notes as a platform for their blogging activities. Roughly $30 \%$ indicated that they use "other blogging platform" (local known Diesel, Namba blogging platforms). Eleven percent said they use Wordpress, followed by Blogger (8\%), Kloop (7\%), Tumblr (5\%), and LiveJournal (3\%). 
Thirty percent of all participants had been blogging at least one year to less than three years when data were collected. Approximately, 29\% of all participants had been blogging for at least three years. Sixteen percent said that they have been blogging for less than a month while $13 \%$ said they had blogged for more than six months but less than a year. The remaining included $6 \%$ blogged one month but less than three months followed by $6 \%$ blogged more than three but less than six months.

Twenty four percent of bloggers said that they blog 2-6 times per week, followed by $22 \%$ indicated that they blog less than a month. Twenty percent blogged multiple times a day when data were collected, followed closely by $19 \%$ who blogged several times a month. Roughly $14 \%$ said that they blogged once a day.

The authors adapted 15-statement questionnaire of motivations from previous research (Chen, 2015; Johnson \& Yang, 2009). Respondents indicated the level of agreement or disagreement where 1 = strongly disagree; 2 = disagree; 3 = neither agree nor disagree; $4=$ agree; 5 = strongly agree. The statements included that I blog: to express myself freely, to get information, to learn interesting things, to meet new people, to share information, to participate in discussions, to have fun, to be entertained, to relax, to pass the time, to communicate with many people at the same time and to keep up with my family and friends.

\section{Results}

Research question 1 asked, what are Kyrgyz internet users' primary motivations for blogging? To answer this question, a principal components analysis with varimax rotation was conducted on the 15-item motivation measurement. The Kaiser-Meyer-Olkin measure verified the sampling adequacy for the analysis, $\mathrm{KMO}=.85$. It is well above the acceptable limit of .5 (Field, 2013). An initial analysis was run to obtain eigenvalues for each factor in the data. Three factors (Table 1) had eigenvalues over criterion of 1 and in combination explained $52.87 \%$ of the total variance. However, a scree plot test was also used in determining factors to keep.

The items that cluster on the same factor suggest that factor 1 represents information motivation that consisted of six indicators, accounting $32.16 \%$ of the data's total variance. The second factor represents recreation that consisted of four indicators and accounted 
$13.50 \%$ of total variance. The third factor represents engagement that consisted of five indicators and accounted for $7.21 \%$ of total variance. Indicator "to participate in discussions" loaded on both information and engagement factors. It was included on the information because of its higher loading there. Another indicator "to communicate more easily" loaded both on information and recreation factors. It was included on the recreation factor because of its higher loading there. The indicator "to have fun" loaded on all three factors. It was included on the engagement because of its higher loading there.

Reliability analyses were conducted for each factor, and they were averaged into indices. Information $(M=3.71, S D=.76$, Cronbach's alpha $=.75)$ and recreation $(M=3.27, S D=$ .87 , Cronbach's alpha $=.74)$ while engagement's reliability was acceptable $(M=3.78, S D=$ .78 , Cronbach's alpha $=.73$ ).

Table 1

Factor analysis (principal component analysis with varimax rotation) of 15 measures of motivations for blogging, $N=224$.

\begin{tabular}{llllll}
\hline Variables & $M$ & $S D$ & Factor 1: & Factor 2: & Factor 3: \\
& & & Information & Recreation & Engagement \\
\hline To meet new people & 3.54 & .96 & .65 & & \\
To give or receive advice & 3.36 & .96 & .65 & \\
To communicate with many & 3.42 & 1.15 & .64 & \\
people at the same time & & & & .36 \\
To participate in discussions & 3.50 & 1.08 & .63 & \\
To communicate more easily & 3.00 & 1.14 & .57 & \\
To keep up with family and & 3.30 & 1.15 & .43 & .80 & \\
friends & & & & .74 & .76 \\
To see what others are up to & 2.80 & 1.17 & & .64 \\
To be entertained & 3.09 & 1.11 & & \\
To relax & 3.04 & 1.05 & & \\
To pass the time & 2.91 & 1.13 & & \\
To express myself freely & 2.83 & 1.30 & & \\
To get information, facts, & 3.41 & 1.09 & & \\
links, news, knowledge, etc & & & & & \\
\end{tabular}


To learn interesting things

.97

.65

$\begin{array}{lllll}\text { To share information, facts, } & 3.51 & 1.03 & .43\end{array}$

links, news, knowledge, etc

To have fun

$\begin{array}{lll}3.42 & 1.01 & .38\end{array}$

.31

.40

Eigenvalues

4.82

2.02

1.08

$\%$ of total variance explained

32.16

13.50

7.21

Cronbach's $\alpha$

.75

.74

.73

Responses were coded 1 (strongly disagree) to 5 (strongly agree).

$M=$ means

Research question 2 asked whether gender played a role in blogging motivation. To answer this question, a one-way MANOVA was used to compare the means of bloggers for three types of motivations, namely; information, recreation, and engagement. The multivariate result was not significant for gender. Thus, male and female participants were not significantly different in their motivations of blogging, $\operatorname{Lambda}(3,259)=.98, p>.05$. Table 2 displays the means for male and female bloggers in motivations

Table 2

The means for male and female bloggers in motivations

\begin{tabular}{llll}
\hline Motivations & Gender & Means & SD \\
\hline Information & Female & 3.79 & .69 \\
& Male & 3.65 & .85 \\
Recreation & Female & 3.31 & .81 \\
& Male & 3.22 & .98 \\
Engagement & Female & 3.86 & .78 \\
& Male & 3.65 & .78 \\
\hline
\end{tabular}

Note: $\mathrm{SD}=$ standard deviations

Research question 3 asked what motivations are the strongest predictors of frequency of blogging. To answer this question, a multiple linear regression was calculated to predict 
participants' blogging frequency based on their motivations. Collectively, when all variables (information, recreation and engagement) were entered, a significant regression equation was found $(F(3,259)=6,292, p=.001)$, with an $\mathrm{R}$ square of .068. It suggests that approximately $6.8 \%$ of the variance in blogging frequency can be explained by the differences in the type of motivation. Engagement was the strongest predictor of blogging frequency $(\beta=.22, p<.05)$ although recreation motivation also showed a statistically significant but negative relationship $(\beta=-.17, p<.05)$. The information motivation was not significantly related to the blogging frequency.

\section{Discussions}

The goal of this study was to understand motivations of Kyrgyz internet users in blogging, the former Soviet Union country that restricts freedom of speech and freedom of the press. A main contribution of this work is to provide exploratory analysis of primarily motivations of internet users in blogging, the country where little academic research has appeared since its independence from Soviet Union in 1991. Blogging was of particular interest in this country because internet is still relatively new and remains the only venue for citizens to express themselves without fear of repercussions (Kulikova \& Perlmutter, 2007).

The main finding of this study is that internet users are motivated to blog as a way to fill information needs such as blogging to give or receive advice, to meet new people, to keep up with family and friends. This finding supports the arguments of previous studies (Kulikova \& Perlmutter, 2007) because access to information is so much restricted in this country. Therefore, people use blogging to meet their information needs, that is something denied by their own government not just for ordinary people but even for journalists. For example, certain topics are prohibited for journalists to report about such as Kyrgyzstan's pro-Russian position, about the President Almazbek Atambayev, LGBT and many others (Uraliev, June 16, 2016; Kurambayev, 2017), certain institutions may refuse to provide any requested information or journalists have to wait many weeks or even months to get requested information from government agencies/officials. In such context, Kulikova and Perlmutter (2007) argued that blogosphere did become an important and oftentimes the only source of information not available from other local sources or the world press for Kyrgyzstan people. 
Results also show that internet users are also motivated to meet their recreation needs such as to be entertained by blogging, to relax and/or simply to pass the time through blogging. It confirms with Nyre and O'Neill (2012) who concluded that three types of motivation for anyone to participate in blogging. They identified private enjoyment and social attractions as being the top two motivations, while political change was the third reason. The third motivation in this current study was engagement need that confirms the existing literature about Kyrgyzstan internet users. Ibold (2010) argued that internet users of Kyrgyzstan lacked "motivations to get involved and take actions on issues that are personally relevant" (p. 533). He also argued that it is unlikely that their online behavior can have an effect in offline. In addition, the findings contradict existing literature that gender does indeed matter in what motivates internet users to blog (Chen, 2012; Pedersen \& Macafee, 2007; Fullwood et al., 2015). This suggests that male and female bloggers in this sample did not differ significantly in their motivations of blogging. Further studies are needed to examine this phenomenon.

Finally, results show that engagement motivation was the strongest predictor of blogging frequency, while recreation motivation showed negative relationship. This indicates that those internet users with recreation motivation tend to blog less than those bloggers with information and/or engagement motivations. It is an interesting finding that contradicts other studies. For example, Chen (2015) argued that recreation motivation outweighs other motivations in predicting the frequency of social media use. Therefore, further studies may be needed to understand the reasons.

A great deal of research has explored motivations of bloggers (Chen, 2012; Li, 2007; Lu \& Hsiao, 2009; Bronstein, 2012; Pedersen \& Macafee, 2007; Sepp et al., 2011) that this study considered. However, this study provides new knowledge by focusing on the specific context of Kyrgyz Republic that received little scholarly attention in the past.

\section{Practical Implications}

From practical standpoint, these findings suggest a number of thoughts. People in Kyrgyzstan lack access to information because of government's restrictions and therefore they rely on internet via different platforms to meet their information needs. For organizations and companies trying to reach wider segment of population, blogging platforms are currently the best venue to deliver their messages and information. For Kyrgyz government, it is important 
to move more toward e-government facilitating access to information that matters people on a daily basis. Internet uses for recreation purpose such as entertainment or simply kill the time via blogging. This suggests that those emerging platforms and websites could have entertainment features to keep attracting the social media users; otherwise, internet users may move elsewhere on the internet. And finally, the findings broadly fit with wider explanation of uses and gratifications theory. The theory argues that people use blogging because they have certain needs, either information need or recreation or simply engagement one and that people gratify these needs by blogging.

\section{Limitations and future research}

It is important to acknowledge several limitations of this study. First, the data for this study was collected through nonprobability sampling and therefore, it is impossible to generalize the finding to a wider population. Second, female participants are overrepresented in this study. Another source of error may come from self-reports, and that participants may lie in their responses.

Future research should explore motivations of internet users beyond blogging platforms in this country where government restricts freedom of expression and access to information. Age factor could be examined in future studies to see whether it would yield different finding. Another future opportunities lies in examining the content of these blogging posts to examine what issues are more frequently discussed on their blogs. And finally, similar studies have previously been undertaken elsewhere.

\section{Conclusion}

In summary, this study takes an exploratory study of motivations of bloggers in Kyrgyz Republic. Clearly, information motivation was the strongest motivation and recreation played a role in why Kyrgyz people blogged, as did engagement motivation. This study provided an early look at the motivations of why internet users blog in a relatively restricted part of Asia for independent researchers and how different motivations relate to blogging use. Finally, this study suggested that gender did not matter in reasons of blogging among the sample participations. 


\section{References}

BBC. (2004). "Blog Picked as the Word of the Year.” BBC, December 1. Retrieved from http://news.bbc.co.uk/2/hi/technology/4059291.stm.

Bowe, B., Freedman, E., \& Blom, R. (2012). Social Media, Cyber-Dissent, and Constraints on Online Political Communication in Central Asia, Central Asia and Caucasus, 13(1), 144-152.

Bronstein, J. (2012). Blogging Motivations for Latin American Bloggers: A Uses and Gratifications Approach. In Dumova, T., \& Fiordo, R.,Blogging in the Global Society: Cultural, Political and Geographical Aspects (pp. 200-215). Hershey, PA: IGI Global Publishing.

Bruns, A. (2006). The Practice of News Blogging. In A. Bruns, \& J. Jacobs, Uses of Blogs (pp. 11-22). New York: Peterlang.

Bahnisch, M. (2006). The Political Use of Blogs. In A Bruns, \& J, Jacobs. Uses of Blogs (pp. 139-150). New York: Peterlang.

Cardoso, G., Liang,G., \& Lapa, T. (2013). Cross National Comparative Perspectives from the world internet project. In W. Dutton (1st ed.). Oxford handbook of internet studies (pp. 216-236). Oxford, UK: Oxford University Press.

Calingaert, D. (2010). Autoritarianism vs. the Internet. Policy Review, 160, 63-75. Retrieved from EBSCOhost.

Chen, G. (2012). Why do women write personal blogs? Satisfying needs for self-disclosure and affiliation tells part of the story. Computers in Human Behavior, 28: 171-180.

Chen, G. (2015). Why do women bloggers use social media? Recreation and information motivations outweigh engagement motivations. New Media \& Society, 17(1): 2440.

Cheong, P., Halavais, A., \& Kwon, K. (2008). The Chronicles of Me: Understanding Blogging as a Religious Practice. Journal of Media and Religion, 7(3): 107-131.

DeGroot, J. \& Carmack, H. (2012). Blogging as a Means of Grieving. In T. Dumova, \& R. Fiordo. Blogging in the Global Society: Cultural, Political and Geographical Aspects(pp. 161-177). Hershey, PA: IGI Global Publishing.

DeYoung, A. (2010). Lost in Transition: redefining students and universities in the contemporary Kyrgyz Republic. Charlotte, NC: Information Age Publishing. 
Djanibekova, N. (June 23, 2017). EurasiaNet.org: Kyrgyzstan: Male MPs Ditch Parliament During Discussions on Women's Rights. Retrieved on August 10, 2017, from http://www.eurasianet.org/node/84111

Dumova, T. \& Fiordo, R. (2012). Blogging in the global society: cultural, political and geographic aspects. Hershey, PA: IGI Global Publishing.

Field, A. (2013). Discovering statistics using IBM SPSS Statistics: and sex and drugs and rock ' $n$ ' roll (fourth edition). London: Sage publications.

Freedom House. (2015). Freedom on the Net 2016. Available at: https://freedomhouse.org/report/freedom-net/2016/kazakhstan (accessed August 11, 2017).

Freedman, E. \& Shafer, R. (2012). Advancing a Comprehensive Research Agenda for Central Asian Mass Media. Media Asia, 39(3): 119-126.

Freedman, E. (2012). Deepening shadows: The eclipse of press rights in Kyrgyzstan. Global Media and Communication, 8, 47-64.

Fullwood, C., Nicholls, W., \& Makichi, R. (2015). We have got something for everyone. How individual differences predict different blogging motivations. New Media and Society, 17(9): 1583-1600.

Global Voices. (July 31, 2017). Tajik Parliament Plans to Monitor Citizens Who Visit 'Undesirable' Websites. Retrieved on August 9, 2017, from https://advox.globalvoices.org/2017/07/31/tajik-parliament-plans-to-monitorcitizens-who-visit-undesirable-websites/\#

Ibold, H. (2010). Disjuncture 2.0: youth, Internet use and cultural identity in Bishkek. Central Asian Survey, 29(4): 521-535.

Katz, E., Blumbler, J., \& Gurevitch, M.(1974). Utilization of mass communication by the individual. In J. Blumber, \& E. Katz,The Uses of mass communication: Current perspectives on gratifications research (pp.19-34). Beverly Hills, CA: Sage.

Kendzior, S. (March 8, 2015). The Future of Central Asian Studies: A Eulogy. Retrieved from https://sarahkendzior.com/2015/03/08/the-future-of-central-asian-studies-aeulogy/.

Kloop.kg. (October 2, 2015)."Анатомия": Политический троллинг в Кыргызстане.

Retrieved from http://kloop.kg/blog/2015/10/02/anatomiya-politicheskij-trolling-vkyrgyzstane/. 
Kulikova, S.(2007). New Media in New Democracoes. Perceptions of Good Governance Among Traditional and Internet-Based Media Users in Kyrgyzstan. Unpublished doctoral dissertation, Louisiana State University. Baton Rouge, Louisiana.

Kulikova, S., \& Perlmutter, D. (2007). Blogging down the dictator: The Kyrgyz revolution and samizdat websites. International Communication Gazette, (69): 29-50.

Kurambayev, B. (2016). Journalism and democracy in Kyrgyzstan: the impact of victimizations of the media practitioners. Media Asia, 43(2), 102-111.

Kurambayev, B. (2017). Bribery and Extortion in Kyrgyz Journalism or Simply Profitable Profession? Asia Pacific Media Educator, 27(1), pp. 170-185.

Li, D. (2007, May 24). Why do you blog: a uses and gratifications inquiry into bloggers' motivations. Paper presented at the annual meeting of the International Communication Association, San Francisco, CA.

Lu, H. \& Hsiao, K. (2009). Gender differences in reasons for frequent blog posting. Online Information Review, 33(1):135-156.

Martin, D. J., \& Schoenbach, K. (2016). Predictors of blogging activities in six Arab countries. International Communization Gazette, 78(8), 733-754

McGlinchey, E., \& Johnson, E. (2007). Aiding the Internet in Central Asia. Democratization, 14 (2): 273-288.

Muscanell, N., \& Guadagno, R. (2012). Make new friends or keep the old: Gender and personality differences in social networking use. Computers in Human Behavior 28(1): $107-112$

Niyazbekov, N. (November 30, 2016). Kazakhstan jails activists, plans a Great Firewall to stifle online dissent. Retrieved from http://www.huffingtonpost.com/theconversation-global/kazakhstan-jails-activist_b_13324548.html.

Nyre, L., \& O'Neill, B. (2012). For and Against Participation: A Hermeneutical Approach To Participation in the Media. In H. Bilandzic., G. Patriarche., \& Traudt P. The Social Use of Media: Cultural and Social Scientific Perspectives on Audience Research (pp. 201-219). Chicago, IL: University of Chicago Press.

Pearce, K. \& Kendzior, S. (2012). Networked Authoritarianism and Social Media in Azerbaijan. Journal of Communication, 62(2): 283-298

Pedersen, S., \& Macafee, C. (2007). Gender Differences in British Blogging. Journal of Computer-Mediated Communication, 12: 1472-1492. 
Pitts, G. (2011). Professional among Journalists in Kyrgyzstan. In E. Freedman., \& R. Shafer, After the czars and commissars: Journalism in authoritarian post-Soviet Central Asia (pp. 233-243). East Lansing, MI: Michigan State University Press.

Rains, S., \& Keating, D. (2015). An Examination of the Outcomes Associating with Making Public, Written Disclosures about Health. Communication Research, 42(1): 107133.

Ryabinska, N.(October 9, 2013). New media and democracy in post-Soviet countries. New Eastern Europe. Retrieved from http://www.eurozine.com/pdf/2013-10-09ryabinska-en.pdf

Savchenko, I. (2016). Kazakhstan: The oppression of journalists and bloggers. Open Dialogue Foundation. Retrieved from http://en.odfoundation.eu/a/7228,kazakhstanthe-oppression-of-journalists-andbloggers.

Shafiev, A. \& Miles, M.(2015). Friends, Foes, and Facebook: Blocking the Internet in Tajikistan. Demokratizatsiya: The Journal of Post-Soviet Democratization, 23(3), 297-319

Sepp, M., Liljander, V., \& Gummerus, J. (2011). Private bloggers' motivations to produce content - a gratifications theory perspective. Journal of Marketing Management, 27(14): 1479-1503.

Schultz, B., \& Sheffer, M. (2008). Resisting change: Blogging and Local sports media. Journal of Communication Studies. 2(4), 372-385.

Srinivasan, R., \& Fish, A. (2009). Internet Authorship: Social and Political Implications Within Kyrgyzstan. Journal of Computer-Mediated Communication, 14(3): 559580.

Tucker, N. (2014, January 24). Sarah Kendzior Says What We Have All Been Afraid to Say... Registan.net. Retrieved January 26, 2014.

http://registan.net/2014/01/26/sarah-kendzior-says-what-we-have-all-been-afraidto-say/

U.N. Women. (n.d.). UN Women in Kyrgyzstan. Retrieved on August 10,2017, from http://eca.unwomen.org/en/where-we-are/kyrgyzstan

Warf, B. (2013). The Central Asian Digital Divide. In R. Massimo., \& G. Muschert., The Digital Divide: The Internet and social inequality in international perspective (pp. 270-271). New York: Routledge. 
Online Journal of Communication and Media Technologies

Volume: 8 - Issue: 2 April - 2018

Wilkinson, C., \& Jetpyspayeva, E. (2012). From Blogging Central Asia to Citizen Media: A Practitioners' Perspective on the Evolution of the neweurasia Blog. Europe-Asia Studies, 64(8), 1395-1414. 